\title{
Left ventricular reconstruction: The aim and the reality after twenty years
}

Vincent Dor, MD

See related article on page 38 .
From the Centre Cardio-Thoracique de Monaco, Monte Carlo, Monaco.

Received for publication Feb 3, 2004; accepted for publication Feb 25, 2004.

Address for reprints: Vincent Dor, MD, Centre Cardio-Thoracique de Monaco, 11 bis, Avenue d'Ostende, Cedex Monte Carlo MC 98004, Monaco (E-mail: vdor@ ccm. $\mathrm{mc})$.

J Thorac Cardiovasc Surg 2004;128:17-20

0022-5223/\$30.00

Copyright (C) 2004 by The American Association for Thoracic Surgery

doi:10.1016/j.jtcvs.2004.02.026

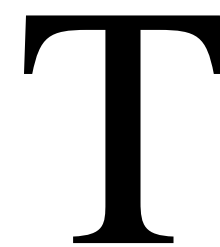

he Cleveland Clinic group's article in this issue, entitled "Neurohormonal Response to Left Ventricular Reconstruction Surgery in Ischemic Cardiomyopathy" and written by Schenk and collaborators, ${ }^{1}$ is excellent. It should be read by cardiac surgeons and I hope by cardiologists, because its synthesis is a well-based confirmation that ischemic dilated failing ventricles can be improved by endoventricular circular reorganization. What a long way we've come since 1984, when all presentations of this technique to surgical and medical audiences were followed only by skeptical questions.

I appreciate the use by Schenk and collaborators ${ }^{1}$ of the term "left ventricular reconstruction" (LVR), which avoids the confusion contained in the inappropriate "surgical remodeling" and is equivalent to the other names given later to the same procedure, such as "endoaneurysmorrhaphy" or "surgical ventricular restoration." The last word has, for the French, a poor political connotation.

This technique has been used since 1984, and the results of this serious, complete, precise, didactic article, coming from a renowned institution, allow us to assess whether the reality is in concordance with the aim. This technique was established to optimize the surgical procedure of extensive blind endocardiectomy proposed by Josephson and colleagues ${ }^{2}$ to treat intractable recurrent ventricular tachycardias before the implantable defibrillator era. The goal was to improve the results, which were excellent for reducing lethal arrhythmias but extremely poor for augmenting left ventricular performance.

The aim of LVR was to use a circular patch sutured inside the ventricle on contractile myocardium to exclude all nonresectable asynergic areas (primarily septal), to reorganize the curvature of the distended wall, and to do all this without excessive volume reduction of the left ventricular cavity. I fully agree with four important points focused on by Schenk and collaborators ${ }^{1}$; however, another point is questionable and yet another must be discussed.

\section{Point One}

The 15 patients enrolled in the Cleveland Clinic studies had true ischemic dilated failing ventricles with congestive heart failure (CHF), very poor left ventricular performance (ejection fraction [EF] $23.9 \%$ ), mitral regurgitation in 5 cases (30\%$50 \%$ ), and very large ventricular volumes (left ventricular end-diastolic volume index [EDVI] $140 \mathrm{~mL}$, left ventricular end-systolic volume index [ESVI] $90 \mathrm{~mL}$ ), with dyskinetic aneurysm being rare. This enhances the observation by Klein, Herman, and Gorlin ${ }^{3} 35$ years ago that there is a continuum between akinesia and dyskinesia in the postischemic left ventricular wall, even though many surgeons and cardiologists still believe there is a fundamental difference between true dyskinetic aneurysms and akinetic aneurysms, with the latter not suitable for surgery. For true dyskinetic aneurysms, with a well-defined delimited neck, resection of anterior fibrotic tissue followed by simple linear suture of the neck has given excellent results since 1958, even if morphologic and hemodynamic parameters are not really optimized, as argued by Froehlich and colleagues. ${ }^{4}$

Retrospective series analyzing around 100 cases spread out over more than 10 years that found no difference between linear suture and endoventricular circular reconstruction are not reliable because only dyskinetic aneurysms are considered. 
When data on the degree of remodeling and volume reduction are considered, several recent series have shown the contrary. ${ }^{5}$

In addition, there has been a decrease in pure dyskinetic aneurysms resulting from transmural infarction as modern treatment of acute myocardial infarction by coronary artery recanalization saves the subepicardial myocardium but leaves subendocardial scar, which more often is akinetic. Today there are more survivors after severe large myocardial infarction but with a scarred "mixed" wall. This may explain the increase of ischemic CHF in the population.

Therefore, differentiating between the two types of scar is not relevant. The assessment of percentage of asynergic wall is more important. The classic opinion of cardiologists that "surgery is contraindicated in postinfarction cardiomyopathy in the absence of ischemia suitable for revascularization,"4 which was based on poor results of linear suture, has to be revised.

\section{Point Two}

Endoventricular circular reconstruction was found to be effective for these large ischemic failing ventricles with CHF. There was a low early operative mortality, and later there was a gain of 1 New York Heart Association functional class, a gain of 12 points of $\mathrm{EF}$, and normalization of EDVI $(90 \mathrm{~mL})$ at 3 months. ${ }^{1}$ This finding confirms data already published, and it is time for cardiologists to change their opinion. Although the Cleveland Clinic article concerns only cases of large ventricular dilatation with CHF, which generally represents the main indication for LVR, two other categories of indication are worth discussing. (1) In an emergency, when mechanical complication of anteroseptal-apical infarction, mainly septal rupture, has to be corrected, the exclusion of necrotic tissues by an endoventricular patch anchored at the limit between normal and necrotic myocardium represents the more effective way to exclude the lesion and improve the left ventricular function.

(2) When surgical revascularization is indicated for a patient with a large asynergic area ( $>35 \%-40 \%$ of left ventricular circumference), even in the absence of CHF and moderate decrease of EF, the LVR can be accomplished during the procedure with reshaping to a normal left ventricle without additional risk. Such a case is called case an "opportune" indication.

\section{Point Three}

LVR should always be associated with complete coronary revascularization and mitral repair if needed. This point must be emphasized. Endoventricular repair allows complete revascularization, chiefly on the anterior wall of the left anterior descending (LAD) coronary artery and its branches, because the repair does not obliterate the epicar- dial left anterior descending coronary artery as do linear and transmural repairs.

\section{Point Four}

The neurohormonal follow-up confirms the role of this complex response in the evolution of remodeling. The decreases in norepinephrine, plasma renin activity, and brain natriuretic peptide levels after LVR are proof that remodeling is a surgically reversible process. However, research on the trigger and not just the consequences for this reaction must be done to identify the cause. The neurohormonal reaction is the witness to left ventricular impairment and dilatation but is not itself the trigger. The trigger for remodeling is the scar. Assessing its size is mandatory, whether by the centerline method, angiography, radionuclide technetium sestamibi, or gadolinium late enhancement during magnetic resonance tomography, which is specific for necrotic and nonviable tissue. If the asynergic wall affects more than $20 \%$ of the surface, or more than $50 \%$ of the left ventricular circumference, the evolution to progressive dilatation is inescapable. Cardiovascular magnetic resonance is the most simple, reliable, and noninvasive technique to follow up the size of asynergy and left ventricular volume regularly, weeks and months after infarction. It is also logical in cases of severe ischemic cardiomyopathy, with EF less than $30 \%$, to ask to cardiologists to wait for magnetic resonance assessment and analysis for the potential for surgical repair, before prophylactic defibrillator implantation, as proposed in the Multicenter Automatic Defibrillator Implantation Trial (MADIT). ${ }^{6}$ Perhaps one day nonferrous devices for pacemakers and defibrillators will become available.

\section{Point Five}

The need for a beating heart in LVR is questionable. The advantage of reducing ischemic time is small, because endoventricular reconstruction itself takes only 20 to $30 \mathrm{~min}-$ utes compared with the 40 to 60 minutes needed for complete coronary revascularization and mitral repair, which are generally conducted on the arrested heart.

The technique of delineation by palpation is limited to the anterior and lateral walls, because the septum cannot be palpated between two fingers through the left ventricular opening. The septum is easy to analyze during endocardiectectomy. If there is a doubt, brief unclamping of the thoracic artery implanted on the left anterior descending coronary artery shows precisely where bleeding myocardium starts. If anterolateral wall is fibrotic and thin, palpation is useless. If this wall is thick, there is no reason to resect or exclude it. The advantage of a quiet, arrested heart, is the ability to conduct full complete endocardiectomy more easily, quickly, and deeply, to set the endocardial sutures more precisely, and above all to insert and inflate a 
rubber balloon mandril at the desired diastolic volume of the patient. Tying the purse-string suture is therefore controlled by setting the size and shape of the neoneck. This maneuver is impossible on a beating heart. The Cleveland Clinic proposes assessment of the diastolic volume by transesophageal 2- or 3-dimensional echocardiography, but this is time-consuming. I confess that the cardiologists at my institution are not able to assess the diastolic volume of an empty beating ventricle by 2- or 3-dimensional echocardiography. In addition, looking carefully many times at films presented by supporters of palpation, I have never clearly seen the type of ischemic disease frequently operated on that shows such a thick and bleeding myocardium. I noticed recently with pleasure that Macey and associates ${ }^{7}$ hold the same opinion regarding the beating-heart technique.

\section{Point Six}

To patch or not to patch? In this article $^{1}$ as in others, ${ }^{8}$ McCarthy's group emphasizes the lack of need for a patch for endoventricular circular reconstruction. I am convinced of the usefulness of a patch, not for historical reasons (because endoventricular patch was the first technique described), not for technical reasons (even if it is the safer way to close the ventricle and avoid bleeding), but to accomplish the aims of LVR: circular reorganization of the remaining cavity with maintenance of a reasonable physiologic cavity-too small is as dangerous as too large.

Obviously, if after tying of the endoventricular suture, the remaining orifice is $1 \mathrm{~cm}$ in diameter or less, direct suture is possible. In my group's series we call this category of LVR-which represents fewer than $10 \%$ of our cases _ "modified Jatene technique." But when the remaining neck is larger than 2 or $3 \mathrm{~cm}$ in diameter, suturing it directly either transversely or horizontally is risky, because there is distortion of the circular reconstruction and possible excess volume reduction. In addition, in very large asynergy, affecting $80 \%$ of the left ventricular wall, when just a small basal and posterior contractile wall remains after exclusion of the two thirds of the septum and apex and almost all the anterior wall, it is impossible to reapproximate the septum and the lateral wall directly. A patch is the only way to rebuild the cavity.

It is wrong to argue that a patch is merely akinetic tissue to replace an akinetic scar, because this patch 2 or $2.5 \mathrm{~cm}$ in diameter represents less than $10 \%$ of the left ventricular circumference (whereas the scarred asynergic area is usually $>50 \%$ ) and the patch anchored on contractile myocardium follows the systolic and diastolic movement without dyskinesia, and this is seen on angiography or magnetic resonance imaging after the operation.

This discussion concerns antero-septo-apical locations, but for posterior locations there is no other option after endocardiectomy on posterior wall and septum with repair or replacement of mitral valve but to place a triangular patch, with the base inserted on the mitral annulus and the apex on the root of the posterior papillary muscle, to rebuild a normal cavity. Since 1984, we have been concerned by the size of the remaining left ventricular cavity after endocardiectomy. The Fontan "trick" was a real improvement, but the degree of tying remains a problem. Tying excessively leads to a very small neck and potential overcorrection. Excellent immediate results with spectacular increase in EF can occur, but there is a risk of secondary severe pulmonary hypertension. Two patients in my group's initial series in the 1980 s needed heterotopic heart transplantation. I have also the recollection of many colleagues who at first were enthusiastic about the endoventricular circular patch plasty, later asking whether others had experience with secondary enlargement of the patch as a result of delayed failure. My group was also concerned when analyzing data after 1 to 5 years $^{9,10}$ to see that in some cases, despite excellent hemodynamic data at 1 month and 1 year, there was progressive deterioration with increase in pulmonary pressure, not always related to mitral regurgitation.

This is the reason why the balloon sizing of the remaining cavity has been used at my institution since 1998. The effects of this technical detail are in the process of being published. We prefer to have a less cosmetic elliptic shape and a less impressive gain in EF, but with a more stable result.

The results obtained by authors of the Cleveland Clinic article at 3 months and 1 year are excellent, but they mentioned a secondary deterioration in $10 \%$ of cases after 1 year. ${ }^{1}$ I do not say that controlling the diastolic cavity of the left ventricle entirely resolves the problem of delayed disappointing results. There are many other potential causes: neglected mitral regurgitation, evolving coronary disease, delay between infarct and repair, and persistence of remodeling evolving like an autoimmune disease. However, avoiding the consequence of a lack of a diastolic capacity can be controlled. My friend Lorenzo Menicanti is now also using a balloon (preformed) with the same goal. He advises me that he, like McCarthy, after using direct suture of the neck in many cases is now going back to using a patch more liberally.

\section{Conclusion}

To conclude these remarks on this excellent work of the Cleveland Clinic Foundation on LVR, it can be said that the reality confirms the aim of this technique, which is to improve left ventricular function deteriorated by dilatation, distortion, and lack of contractility, which form the substratum of CHF in ischemic cardiomyopathy. In the same way that indications for surgery in valvular diseases have changed (surgery before permanent cardiac enlargement and failure, when regurgitation or gradient are severe), 
indications for LVR for ischemic wall motion abnormalities must change. Skeptical surgeons and cardiologists must change their minds, because there is a place for LVR in the treatment of large ischemic wall motion asynergies. This surgery is possibly more efficient in the following weeks or months after infarct than in the following years. Assessing the extent of asynergic left ventricular wall after infarction is a must.

\section{References}

1. Schenk S, McCarthy PM, Starling RC, Hoercher KJ, Hail MD, Otaki $\mathrm{Y}$, et al. Neurohormonal response to left ventricular reconstruction surgery in ischemic cardiomyopathy. J Thorac Cardiovasc Surg. 2004; 128:38-43.

2. Josephson ME, Harken AH, Horowitz LN. Long-term results of endocardial resection for sustained ventricular tachycardia in coronary disease patients. Am Heart J. 1982;104:51-7.

3. Klein MD, Herman MV, Gorlin R. A hemodynamic study of left ventricular aneurysm. Circulation. 1967;35:614-30.
4. Froehlich RT, Falsetti HL, Doty DB, Marcus ML. Prospective study of surgery for left ventricular aneurysm. Am J Cardiol. 1980;45:923-31.

5. Lundblad R, Abdelnoor M, Svennevig JL. Repair of left ventricular aneurysm: surgical risk and long-term survival. Ann Thorac Surg. 2003;76:719-25

6. Moss AJ, Zareba W, Hall WJ, et al. Prophylactic implantation of a defibrillator in patients with myocardial infarction and reduced ejection fraction. N Engl J Med. 2002;346:877-83.

7. Maxey TS, Reece TB, Ellman PI, Kern JA, Tribble CG, Kron IL. The beating heart approach is not necessary for the Dor procedure. Ann Thorac Surg. 2003;76:1571-5.

8. Caldeira C, McCarthy PM. A simple method of left ventricular reconstruction without patch for ischemic cardiomyopathy. Ann Thorac Surg. 2001;72:2148-9.

9. Dor V, Sabatier M, Di Donato M, Maioli M, Toso A, Montiglio F. Late hemodynamic results after left ventricular patch repair associated with coronary grafting in patients with postinfarction akinetic or dyskinetic aneurysm of the left ventricle. J Thorac Cardiovasc Surg. 1995;110: 1291-301.

10. Di Donato M, Sabatier M, Dor V, Gensini GF, Toso A, Maioli M, et al. Effects of the Dor procedure on left ventricular dimension and shape and geometric correlates of mitral regurgitation one year after surgery. J Thorac Cardiovasc Surg. 2001;121:91-6.

Access to The Journal of Thoracic and Cardiovascular Surgery Online is reserved for print subscribers!

Full-text access to The Journal of Thoracic and Cardiovascular Surgery Online is available for all print subscribers. To activate your individual online subscription, please visit The Journal of Thoracic and Cardiovascular Surgery Online, point your browser to http://www.mosby.com/jtcvs, follow the prompts to activate your online access, and follow the instructions. To activate your account, you will need your subscriber account number, which you can find on your mailing label (note: the number of digits in your subscriber account number varies from 6 to 10). See the example below in which the subscriber account number has been circled:

\section{Sample mailing label}

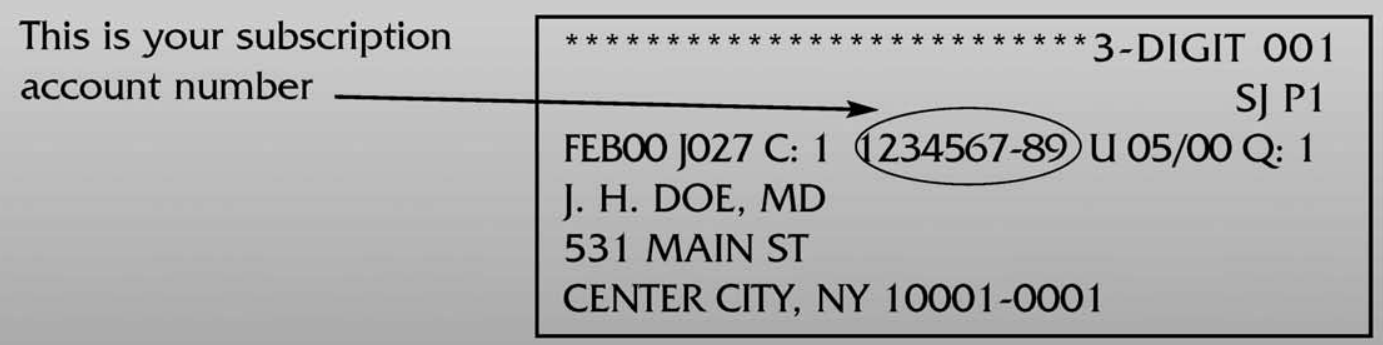

Personal subscriptions to The Journal of Thoracic and Cardiovascular Surgery Online are for individual use only and may not be transferred. Use of The Journal of Thoracic and Cardiovascular Surgery Online is subject to agreement to the terms and conditions as indicated online. 